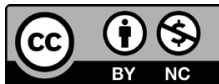

\title{
A FAMÍLIA COMO INSTITUIÇÃO POLÍTICA E A TEORIA DAS CAPACIDADES DE MARTHA NUSSBAUM
}

Family as a political institution and martha nussbaum's capabilities approach

Robison Tramontina

Larissa Thielle Arcaro

\section{RESUMO}

Trata-se de analisar a família como instituição política a partir do enfoque das capacidades de Martha Nussbaum. A dicotomia público/privado serviu/ serve como estrutura conceitual justificadora para restringir a participação das mulheres na esfera política, para inviabilizar a realização de seus projetos pessoais e profissionais e para acobertar o processo de "naturalização" do âmbito doméstico como espaço eminentemente feminino. A partir do questionamento desse par dicotômico, o artigo objetiva demonstrar os avanços teóricos permitidos quando se considera a família como instituição política. Ao se pensar a família como instituição política a ideia de justiça ingressa no ambiente intrafamiliar, o cuidado passa a ser valorizado e o desenvolvimento das capacidades das mulheres é desbloqueado.

Palavras-chaves: Família; Cuidado; Capacidades. 


\section{ABSTRACT}

This paper studies the family as a political institution and Martha Nussbaum's Capabilities approach.The public / private dichotomy is used as a conceptual framework to restrict the participation of women in the political sphere, to make it impossible the realization of their personal and professional projects and to omit the process of "naturalization" of the domestic sphere as an eminently female space. The paper aims to demonstrate the theoretical advances allowed when considering the family as a political institution. The family considered as a political institution allows the idea of justice to enter the family space, that care is valued and the development of women's capabilities is realized.

Keywords: Family. Care. Capabilities.

\section{INTRODUÇÃO}

Ao longo dos séculos, o acesso aos espaços públicos foi negado às mulheres em razão da exigência de atuação no universo privado. 0 argumento justificador de tal recusa assentava-se na tese de que a elas cabia naturalmente as tarefas domésticas de manutenção do lar e do cuidado de crianças, idosos, pessoas com deficiência e doentes. Além disso, de acordo com a maioria dos teóricos políticos até meados do século passado, dizia-se que as restrições aos direitos civis e políticos das mulheres fundava-se na inaptidão intrínseca feminina para atividades fora do lar (OKIN, 1979; KYMLICKA, 2006). O fundamento natural da subordinação e exclusão social das mulheres, com lastro histórico evidente tanto na teoria como na prática, provoca efeitos deletérios e profundos na constituição da personalidade, imagem e autoestima feminina. Não obstante, o caminho evolutivo percorrido nas democracias ocidentais para a proteção e efetivação dos direitos das mulheres e outras medidas estimuladas e aplicadas no âmbito social e econômico, em grande medida, o cenário de desigualdades e restrições permanece.

A dicotomia público-privado, tal como pensada e caracterizada pela teoria política hegemônica, caracteriza a esfera pública como o âmbito da igualdade, reciprocidade e interesse mútuo e a esfera privada como o espaço do amor, do afeto e do cuidado. Tal distinção exclui o ambiente 
doméstico/familiar do escopo da justiça (NUSSBAUM, 2013). Em outros termos, a família não é considerada uma instituição política.

Contudo, se for adotado pressupostos distintos dos construídos historicamente, ou seja, de que a família é uma instituição política, de que o afeto e cuidado são bens sociais básicos, de que o trabalho doméstico se equipara e tem o mesmo valor do trabalho não-doméstico, quais seriam os avanços teóricos que poderiam se configurar? Posto isso, a questão que orienta a presente investigação é a seguinte: quais são os ganhos teóricos de se considerar a desigualdade entre homens e mulheres a partir dos pressupostos acima mencionados?

Nesse sentido, o presente artigo tem por escopo demonstrar as vantagens para as discussões sobre a desigualdade entre homens e mulheres quando se considera, em termos gerais, a família como uma instituição política.

A temática foi escolhida para análise em razão da relevância e da abrangência das questões englobadas nessa seara, sobretudo pelas delicadas problemáticas - não estudadas e deixadas de lado - da divisão sexual do trabalho, da desvalorização do cuidado e do trabalho doméstico.

Assim, a primeira parte do artigo orienta-se pela seguinte premissa: A dicotomia público/privado hierarquiza as dimensões da vida humana e justifica a desigualdade de gênero. Para fundamentá-la, aborda-se a noção, forjada ainda na antiguidade, da dualidade entre as esferas pública e privada e a circunscrição da mulher ao espaço doméstico, enfatizando-se o papel feminino de procriação e de sustentação da vida e a conexão com as divisões de tarefas baseadas no gênero ainda existentes na sociedade atual. Hannah Arendt fornece o suporte na explicitação da proposição acima destacada.

Em seguida, procura-se demonstrar a segunda premissa argumentativa: a divisão sexual do trabalho limita as opções de escolha das mulheres e "naturaliza" o cuidado como atividade feminina. Nesse sentido, são tecidas considerações mais específicas a respeito da divisão sexual do trabalho doméstico e da responsabilização feminina pela atividade do cuidado. Colacionam-se pesquisas elaboradas por organismos governamentais nacionais e expõem-se os impactos negativos à vida das mulheres, decorrentes da rotina diária de trabalho prestado de forma 
gratuita no âmbito do lar e da família. Aqui, Tereza Beleza, Flávia Biroli e Heleieth Saffioti auxiliam na teorização e interpretação dos dados colhidos.

A última parte deste é guiada pela premissa de que o cuidado como tarefa exclusiva da mulher obsta seus "planos de vida' e o não tratamento da família como instituição política dificulta o desenvolvimento das capacidades humanas centrais. Nesse, analisa-se a desigualdade de gênero no desempenho do cuidado sob o enfoque das capacidades desenvolvido por Martha Nussbaum. Primeiramente, são apresentados os contornos essenciais do marco teórico, com destaque à preocupação com a equidade nas relações entre membros familiares e em fornecer substrato para lidar com problemas de justiça no seio da família. Na sequência, são examinadas as questões atinentes às consequências decorrentes da sobrecarga com o cuidado para as capacidades das mulheres.

\section{A DICOTOMIA ENTRE AS ESFERAS PÚBLICA E PRIVADA E A CIRCUNSCRIÇÃO DA MULHER AO ESPAÇO DOMÉSTICO}

O objetivo deste tópico é justificar a primeira premissa do argumento proposto: a dicotomia público/privado hierarquiza as dimensões da vida humana e justifica a desigualdade entre homens e mulheres.

0 pensamento político ocidental tem como uma das suas pilastras centrais a distinção entre a esfera pública e a esfera privada (OKIN, 2008). Surgiu no pensamento grego clássico e se difundiu pelo ocidente por intermédio do direito romano (HABERMAS, 1984). No pensamento grego clássico forjou-se a noção da existência de duas esferas da vida humana, com clara e rígida separação: uma privada e outra pública.

Na visão grega, a pólis era a cidade-estado e a oikos correspondia ao território da casa. Nessa concepção, a capacidade humana de organização política era oposta à associação natural, cujo núcleo fundamental era a família. Sendo assim, o nascimento da cidade-estado concedeu ao "homem", além da vida privada, uma segunda vida, a pública (bios politikos). Desse modo, o cidadão passou a pertencer à duas ordens de existência, havendo nítidas diferenças entre aquilo concernente à vida própria (idion) e ao que era comum (koinon). Não apenas a oposição entre o público e privado 
caracteriza o arcabouço teórico grego sobre a política. Além da distinção já indicada, eles hierarquizavam essas duas ordens da existência humana. Ou seja, a vida pública era superior à via privada. Na primeira, na esfera política, eram exercitadas as duas mais altas atividades humanas, a ação (praxis) e o discurso (lexis). As atividades necessárias e úteis, o trabalho e a produção, eram realizadas na esfera privada, de natureza econômica (ARENDT, 2007).

De acordo com Arendt (2007), os homens ao ingressar na esfera pública desejavam realizar algo, de proposição individual ou compartilhado, transcendente a sua passagem terrena e suas vidas mundanas. Na esfera pública da pólis, as decisões não eram tomadas mediante força ou violência, mas por meio de diálogos e pelo poder do convencimento. Compelir ou obrigar os semelhantes consistia em recurso pré-político, próprio da vida fora da cidade-estado, afeto à esfera privada, na qual o chefe da família dominava e impunha suas determinações.

Assim, o traço distintivo fundamental entre a esfera política e o âmbito da casa, era o fato de que nesta os homens se associavam de forma obrigatória em razão das suas necessidades básicas vitais, para manutenção e sobrevivência da espécie. Nesse contexto, era tido como evidente e incontestável o papel masculino na manutenção individual e o feminino na sobrevivência da espécie, reputando-se como naturais os encargos do homem no fornecimento de alimentos e da mulher no labor do parto (ARENDT, 2007).

Enquanto a família e o lar correspondem a necessidade, a esfera pública da pólis, de modo diverso, representava, exclusivamente, a seara da liberdade. A relação entre as duas esferas reside no fato da vida privada ser a condição de possibilidade da vida pública. Em outros termos, a ausência da necessidade, ou domínio dela, permite o exercício da liberdade por alguns, aqueles liberados da atividade produtiva e reprodutiva. Ou seja, às custas da esfera privada da família, ascendia-se à esfera pública, justificando-se, pois, a força e violência, por serem os meios de os homens superarem as necessidades e atingirem a liberdade, pressuposto à eudaimonia (ARENDT, 2007).

Mais a mais, as relações na pólis se estabeleciam entre pessoas iguais e não havia governantes e governados, diferentemente da família, 
na qual reinava a desigualdade entre os integrantes onde o chefe da família exercia posição de superioridade. 0 conceito de liberdade, para os gregos, perpassava pela igualdade, pela não sujeição às necessidades vitais e pela não dominação por ou sobre alguém, algo impossível na família (ARENDT, 2007).

0 menoscabo à esfera privada por parte dos antigos gregos decorria da compreensão de que, em tal âmbito imperavam a vergonha, a futilidade e a irrelevância de relações não políticas, impossibilitando a expressão no homem daquilo que é verdadeiramente humano, e o transformando em mero exemplar da espécie humana. Aliás, o vocábulo "privado", original e etimologicamente, indica "privação", compreendendo-se que viver somente na esfera restrita do lar implicaria subtração de aspectos da vida verdadeiramente humana exercida na polis: ser visto e ouvido por outros e a possibilidade de realizar algo que se revestisse de permanência ou até mesmo de imortalidade (ARENDT, 2007).

A esfera pública era o espaço da revelação, da transparência, permanecendo no espaço privado, o inexpressável, o ocultado. Nela, escondiam-se as práticas voltadas à subsistência dos indivíduos e à sobrevivência da espécie, mantendo-se, assim, os trabalhadores e as mulheres longe dos olhos, porquanto dedicavam, respectivamente, às funções corporais de cuidar das necessidades físicas da vida e de garantir a sobrevivência física da espécie (ARENDT, 2007). À vista disso, em razão da papel da mulher na esfera reprodutiva, confunde-se a intimidade com o feminino (ALMEIDA, 1997).

Esses fundamentos legitimavam a manutenção das mulheres confinadas no espaço da casa, desempenhando o trabalho, o papel de procriação e de sustentação da vida. As bases da dicotomia entre público e privado guardam, pois, relação umbilical com as classificações/divisões calcadas no gênero, bem como entre cultura e natureza. E tal separação, que põe homens e mulheres em universos apartados, arraigou-se e balizou os pensamentos e as práticas ético-políticas ao longo da história da humanidade, continuando como "uma base inconsciente" até os dias de hoje. Mesmo a ética do liberalismo, nas suas versões predominantes, restringe o atuar feminino à esfera doméstica, voltada para a intimidade, afetividade, aos cuidados e reprodução (PERROT, 1995). 


\section{A DIVISÃO SEXUAL DO TRABALHO DOMÉSTICO E A RESPONSABILIZAÇÃO FEMININA PELA ATIVIDADE DO CUIDADO}

A distinção público/privado impacta diretamente na questão de gênero em todos os países. No Brasil, não é diferente. Pesquisas realizadas pelo Instituto de Pesquisa Aplicada (IPEA) e pelo Instituto Brasileiro de Geografia e Estatística confirmam as consequências da distinção acima mencionada:

a) $90 \%$ das mulheres declararam realizar atividades domésticas não remuneradas, enquanto o percentual dos homens foi de cerca de $50 \%$. Tal proporção sofreu sutil alteração ao longo dos anos estudados (1995-2015), diminuindo, entre as mulheres, de $94 \%$ a $91 \%$ e aumentando de $46 \%$ para $53 \%$ relativamente aos homens (IPEA, 2018).

b) Em 2015, as mulheres trabalhavam semanalmente, em média, 7,5 horas a mais do que os homens (a jornada total das mulheres era de 53,6 horas semanais, enquanto a dos homens era de 46,1 horas), sendo que 6 horas semanais eram dedicadas aos afazeres domésticos (IPEA, 2018).

c) Conforme dados publicados pelo IBGE (2018), as mulheres dedicavam 18,1 horas semanais aos cuidados de pessoas ou afazeres domésticos, isso representa aproximadamente $73 \%$ a mais do que os homens, os quais se ocupavam de tais tarefas durante 10,5 horas semanais.

Os dados das pesquisas indicam: a) a responsabilização das mulheres pelo trabalho doméstico gratuito, padrão persistente e predominante na sociedade brasileira; e b) o exercício de atividade remunerada não interfere nas responsabilidades das mulheres nas atividades domésticas, às quais segue sendo atribuído tal encargo, isso gera à "dupla jornada" (tempo despendido no trabalho remunerado, acrescido do tempo dedicado gratuitamente aos afazeres domésticos). 
O Cenário fático retratado ilustra o argumento desenvolvido no tópico anterior, há uma divisão sexual do trabalho e uma definição prévia dos papéis e funções de cada gênero. A despeito do plano normativo constitucional estabelecer a igualdade entre homens e mulheres, a construção da identidade social deles é confeccionado com base nas obrigações díspares e delimitações dos campos de atuação de cada categoria de gênero, ocorrendo a obstaculização da concretização do ideal de igualdade material. Além disso, perdura a atribuição do espaço doméstico à mulher, bem como o papel feminino tradicional do cuidado e da preparação dos filhos para a vida adulta, o qual é reservado à mulher mesmo se ela desempenhar função remunerada fora do lar (SAFFIOTI, 1990).

Não raramente, observam-se tentativas de naturalização de tal processo, na busca de convencer que a conexão da esfera privada da casa com a mulher se dá em razão da capacidade de maternidade. Assim, naturalmente, incumbiria à mulher "se dedicar aos afazeres domésticos, aí compreendida a socialização dos filhos, como é natural sua capacidade de conceber e dar à luz" (SAFFIOTI, 1990, p. 9).

Nesse sentido, há uma naturalização de um processo históricocultural. Ao se afirmar ser natural a mulher ficar circunscrita ao espaço doméstico, reservando-se o espaço público aos homens, naturaliza-se uma concepção histórica, cultural e socialmente forjada. Trata-se de uma construção diversa e variada, ou seja, cada sociedade molda diferentes significados para o mesmo fenômeno natural, alterando-se a compreensão do ser mulher e ser homem de acordo com cada arranjo social. Em outras palavras, é por meio das interações sociais que as pessoas "se tornam homens e mulheres", evidenciando a construção social da identidade humana. Logo, a feminilidade é construída/inventada (BELEZA, 2010; SAFFIOTI, 1990). Está-se, em resumo, diante da naturalização de uma discriminação de cunho unicamente sociocultural e tal entendimento lúcido pode permitir progressos na conscientização de homens e mulheres, desmistificando o suposto caráter natural (e, portanto, imutável) das discriminações perpetradas contra o gênero feminino (SAFFIOTI, 1990).

Em decorrência disso, percebe-se, prática e teoricamente, uma dinâmica de justificação de um processo de naturalização e hierarquização de lugares e papéis objetivando subordinar às mulheres aos homens. 
A responsabilização desigual de mulheres e de homens pelo trabalho doméstico está na base do sistema patriarcal, no qual as mulheres têm sua força de trabalho apropriada (sem remuneração, nos cuidados com os filhos e familiares e na rotina das atividades domésticas), em benefício dos homens, os quais têm ao seu dispor tempo para o trabalho remunerado e outras atividades em seu tempo livre. Ou seja, os impactos de tal dinâmica não ficam circunscritos ao espaço da família, pois as obrigações assumidas no âmbito familiar cerceiam, tolhem e definem as ocupações e possibilidades fora de casa, provocando rupturas e obstáculos na atividade profissional e conflitos mais agudos entre as exigências da casa e a rotina de trabalho não doméstico (BIROLI, 2018).

Assim, as mulheres ocupam posição onerada pela rotina diária de trabalho prestado de forma gratuita, em razão da divisão sexual do trabalho - um dos pilares das hierarquias de gênero -, sofrendo restrições e desvantagens que moldam seus caminhos e influenciam nas possibilidades de desenvolvimento e participação na esfera pública (inclusive, de integração mais igualitária no âmbito político), impondo empecilhos ao acesso a ocupações, tolhendo o reconhecimento social de suas potencialidades, o poder decisório e autonomia na esfera doméstica, íntima etc. (BIROLI, 2018).

O tempo livre e a renda são, pois, recursos fundamentais, profundamente afetados pelo desequilíbrio entre trabalho remunerado e não remunerado, bem como pelo acesso diferenciado a ocupações. Evidentemente, ficando em casa muito tempo, tomando conta de tarefas do cotidiano da vida doméstica, grande parte constituídas do desempenho de cuidado de crianças, idosos, pessoas com deficiência e doenças, a mulher tem menor número de possibilidades de ser estimulada e de efetivamente desenvolver suas potencialidades (SAFFIOTI, 1990).

Para ilustrar, em pesquisa publicada pelo IBGE no ano de 2018, cujo objeto foi avaliar, entre outras situações, a da educação no Brasil, constatouse que os motivos elencados pelas pessoas entre 15 (quinze) a 29 (vinte e nove) anos de idade para o fato de não estarem estudando variaram substancialmente conforme o gênero da pessoa entrevistada (IBGE, 2018).

A principal razão para os homens estarem fora da sala de aula, com $49,4 \%$, foi o desempenho de trabalho, a busca de emprego ou a obtenção 
de um, cujo início se daria em breve. Entre as mulheres, essa também foi a justificativa mais recorrente, verificada em $28,9 \%$ dos casos. 0 segundo motivo mais comum para os homens $(24,2 \%)$ não estudarem foi a carência de recursos financeiros para pagamento das despesas educacionais (mensalidade, transporte, material escolar etc.), justificativa essa indicada por $15,6 \%$ das mulheres. Relativamente às mulheres, a segunda razão mais apontada para não estudarem, em $24,2 \%$ dos casos, foi precisar cuidar dos afazeres domésticos ou de criança, adolescente, idosos ou pessoa com deficiência. Este motivo foi citado por somente por $0,7 \%$ dos homens, correspondendo à menor percentagem das respostas obtidas entre os indivíduos do sexo masculino (IBGE, 2018).

Com efeito, há dimensões ideológicas (como a "naturalização das competências e das habilidades") e socioeconômicas (remuneração iníqua, decorrente da desvalorização do que é "historicamente associado ao feminino", e acesso a desigual tempo livre) subjacentes à incumbência precípua das mulheres pelo cuidado, constituindo o cerne da problemática "a alocação desigual das responsabilidades", porquanto as mulheres, como visto, desempenham o cuidado das crianças, idosos e de pessoas com deficiência em nível desproporcional em comparação aos homens (BIROLI, 2018, p. 11 e 48).

Nesse cenário, é necessário problematizar as fronteiras entre as esferas pública e privada, as quais, indubitavelmente, definem lugares diferentes para mulheres e homens, responsabilidades desiguais na esfera doméstica e carregam "sentidos do feminino que ainda guardam relação com a noção de domesticidade". Ademais, é necessário considerar as relações de poder na esfera privada para entender "como os indivíduos se tornaram quem são e dos limites desiguais para atuarem, individual e coletivamente", porquanto se trata de "fator que define as possibilidades de atuação na vida pública", na medida em que a atribuição de responsabilidades no âmbito do lar pode "coibir ou facilitar a atuação em outras esferas da vida, entre elas a do trabalho" (BIROLI, 2018, p. 11 e 32).

A família continua, portanto, significando "nexo na produção do gênero e da opressão às mulheres", colocando-as em posição de "vulnerabilidade" e impondo-lhes "constrangimentos materiais que 
constituem as escolhas", "ampliando ou restringindo suas alternativas" (BIROLI, 2018, p. 33/34 e 56).

Conquanto, nas últimas décadas, ocorrem modificações das posições de mulheres e de homens, com transformações nas relações e no entendimento dos papéis de gênero, as disparidades seguem sendo muito significativas, constituindo fatores fundamentais para tal quadro o tempo livre e a renda, determinados pela divisão sexual do trabalho, que, de um lado, opera privilégios e, de outro, desvantagens e opressão (BIROLI, 2018).

\section{FAMILIA E CUIDADO SOB O ENFOQUE DAS CAPACIDADES DE MARTHA NUSSBAUM}

No debate feminista acerca da família e do cuidado, entre muitas outras questões relevantes, contesta-se a dualidade entre o espaço público e o privado, bem como a despolitização das relações na esfera privada, isto é, a não penetração dos requisitos de justiça e dos critérios democráticos para avaliar seus contornos (BIROLI, 2018, NUSSBAUM, 2013; OKIN, 2008). Vários teorias, especialmente feministas, trataram desse tema. Uma delas foi o enfoque das capacidades.

O Enfoque das Capacidades (EC) é uma abordagem desenvolvida por Amartya Sen e Martha Nussbaum. Entre eles existem inúmeros pontos de convergência e alguns pontos de divergência. Sen desenvolve a perspectiva econômica da teoria concentrando-se, inicialmente, na mensuração da qualidade de vida $(1980,1993)$ e, recentemente, nas questões de justiça social (2011). Nussbaum, por outro lado, procura estabelecer a base filosófica da concepção (STRAPAZZON; TRAMONTINA, 2017). Aqui, nos interessa abordagem de Nussbaum.

Nussbaum $(2000 ; 2013)$ centra suas críticas nos pensadores da tradição do contrato social. A tradição contratualista apresenta os seguintes limites: a) não tratam a família como uma instituição política; b) não pensam sobre questões de equidade nas relações entre os membros familiares; c) não fornecem substrato adequados para lidar com problemas de justiça no interior da família. 
De acordo com Nussbaum (2013), as teorias clássicas contratualista são importantes e deram contribuições significativas para o pensamento filosófico. Entretanto, como conservam a divisão entre o público e o privado, apresentam importantes falhas em se tratando da questão da igualdade entre homens e mulheres. Nesse sentido, segundo o argumento nussbauniano, os teóricos clássicos idealizaram agentes contratantes homens, com igualdade de capacidade e de atividade econômica produtiva, excluindo da situação de acordo as mulheres (reputadas não produtivas), as crianças e os idosos, omissões que, em certa medida, foram remediadas nas doutrinas contratualista da atualidade, permanecendo, entretanto, as dificuldades atinentes à concepção da família como uma esfera privada imune à lei e ao contrato.

Para os contratualistas clássicos e contemporâneos, a justiça está restrita ao âmbito do político, logo, na esfera pública. A família como algo "natural" e privado não é objeto de tematização e está imune à justiça. Para o enfoque das capacidades, "a justiça tem sentido onde quer que haja seres humanos", porquanto as pessoas desejam viver conjuntamente e bem, “o que inclui, [...], o viver em acordo com a justiça” (NUSSBAUM, 2013, p. 104).

Neste sentido, a família consiste em uma instituição política moldada essencialmente pela legislação e pelas instituições, e os sentimentos familiares não são naturais, mas produzidos pelos arranjos/influências sociais e pelas expectativas e necessidades que tais fatores impõem à família. Assim, tratar de forma adequada o problema da justiça de gênero perpassa pelo reconhecimento da família como uma instituição política e pelo repensar da cidadania, com reanálise do escopo da cooperação social e a partir da compreensão do cuidado como um bem social primário (NUSSBAUM, 2013).

No enfoque das capacidades, a cooperação social não é entendida como um sistema cooperativo composto por regras e procedimentos políticos reconhecidos e compartilhados fundado na ideia de reciprocidade e vantagem racional (RAWLS, 2000; 2003). Nele, a cooperação social compreende a justiça e a inclusão "como fins de valor intrínseco". As pessoas estão unidas por laços altruísticos e não exclusivamente na vantagem mútua. Para sustentar essa noção de cooperação, Nussbaum faz uso de uma concepção aristotélica/marxista de pessoa: "um animal político e social, 
cujo bem é irredutivelmente social, e que compartilha fins complexos com outras pessoas em muitos níveis" (NUSSBAUM, 2013, p. 195).

Nesse passo, diversamente de John Rawls (que adota visão kantiana de que a pessoalidade reside na racionalidade, fundamento da dignidade humana), o enfoque das capacidades compreende "a racionalidade e a animalidade" totalmente unificadas, reputando a "racionalidade como um aspecto da animalidade". Ademais, a abordagem considerase a necessidade corporal - aí inserida a necessidade por cuidado característica da racionalidade e da sociabilidade, isto é, um aspecto da dignidade (NUSSBAUM, 2013, p. 196/197).

Partindo de tais premissas, a abordagem do enfoque das capacidades objetiva especificar condições necessárias para uma sociedade "dignamente justa", através de um "conjunto de direitos fundamentais para todos os cidadãos”, compreendendo que há violação da justiça básica se não se garantem tais direitos, porquanto "implícitos nas próprias noções de dignidade humana e de uma vida segundo a dignidade humana" (NUSSBAUM, 2013, p. 191).

Dessarte, o enfoque das capacidades objetiva "fornecer a base filosófica para uma explicação das garantias humanas centrais que devem ser respeitadas e implementadas pelos governos de todas as nações, como um mínimo do que o respeito pela dignidade humana requer". Basicamente, a filósofa elenca um rol de "capacidades humanas centrais", defendendo que todas estão "implícitas na ideia de uma vida apropriada à dignidade humana", constituindo a "fonte de princípios políticos para uma sociedade liberal pluralística" (NUSSBAUM, 2013, p. 84).

Além disso, Nussbaum (2013, p. 91/94) entende que as capacidades são "mutuamente assistentes" e que todas ostentam extrema importância para a justiça social, constituindo falha inaceitável que a sociedade se olvide de uma ou de algumas capacidades para fomentar e/ou proteger outras. A lista das capacidades humanas centrais, que é aberta e não é estanque/imutável, é a seguinte: vida; saúde física; integridade física; sentidos, imaginação e pensamento; emoções; razão prática; afiliação; outras espécies; lazer; e controle sobre o próprio ambiente.

Vale destacar que um dos vieses da capacidade de "afiliação" corresponde a "ter as bases sociais de autorrespeito e não humilhação", 
isto é, "ser capaz de ser tratado como um ser digno cujo valor é igual ao dos outros", o que inclui a não discriminação com base no sexo/gênero (NUSSBAUM, 2013, p. 93).

Em síntese, cada uma dessas capacidades é imprescindível, sendo inimaginável, na ótica da autora, que uma vida sem qualquer delas seja condizente com a dignidade humana. Além disso, cuida-se de uma abordagem dos direitos humanos, os quais, como se sabe, guardam relação umbilical com a dignidade humana, visando à sua proteção e promoção (NUSSBAUM, 2013).

Nesse passo, as "posições sociais relativas" das pessoas seriam medidas pelo "grau com que possuem as várias capacidades da lista" e não pela quantidade de renda e riqueza, já que, por exemplo, "uma pessoa pode estar bem em termos de renda e riqueza e, no entanto, ser incapaz de atuar bem no seu local de trabalho por causa das sobrecargas das tarefas de cuidado em casa" (NUSSBAUM, 2013, p. 176).

Relativamente ao cuidado e à lista das capacidades, Nussbaum (2013) entende que, em períodos de dependência, o cuidado figura entre as necessidades primárias dos cidadãos, cuja satisfação, até um nível mínimo, será uma das marcas de uma sociedade dignamente justa; assim, o papel do cuidado deve ser transformado em uma concepção de justiça tão fundamental quanto deve ser. Porém, considerando que não se trata de "uma coisa única", o cuidado não deveria/precisaria ser adicionado à lista como uma capacidade apartada das demais; diante do seu "papel íntimo e básico", o cuidado abarcaria "todo o campo das capacidades humanas centrais".

A sociedade verdadeiramente justa se importa com as(os) cuidadoras(es)/assistentes (sobretudo com a exploração e sobrecarga suportada por essas pessoas), bem como atenta para suas carências, em especial, de reconhecimento de seu trabalho, de assistência, de oportunidades profissionais e participação social e política.

Isso possui íntima conexão com a justiça de gênero, porquanto o cuidado é uma atividade majoritariamente feminina gratuita e não reconhecida como trabalho. É sabido, como destacado no tópico anterior, tais incumbências interferem significativamente na vida das mulheres. E portanto, realizar o trabalho doméstico e do cuidado deveria ser um 
escolha, não uma imposição. Não obstante, persiste amplamente a compreensão de que tal trabalho deve continuar sendo feito gratuitamente, "por amor", pelas mulheres, apesar de redundar em óbices decisivos para sua trajetória em diversos âmbitos da vida (v.g., econômico, já que reduz sua produtividade e oportunidades de ascensão laboral; civil, porquanto sua contribuição resta cerceada; e político, notadamente, pela escassez de tempo e outros obstáculos à participação). As mulheres mostram-se "mais dispostas" a trabalhar em empregos de tempo parcial e a sofrer limitações à sua carreira, em comparação aos homens, não havendo dúvidas de que o trabalho não remunerado realizado na esfera do lar configura uma das maiores fontes de desvantagem para as mulheres.

Cabe salientar, ainda, que nessa conjuntura emergem "preferências adaptativas", isto é, não raramente, algumas mulheres (e outros indivíduos desfavorecidos) "adaptam suas preferências àquilo que acham que podem alcançar e também àquilo que sua sociedade lhes diz ser uma conquista adequada para elas", representando, em verdade, preferências eleitas em "condições injustas de vida" e que caminham no sentido de "validar o status quo" (NUSSBAUM, 2013, p. 88).

A assistência, isto é, o desempenho do cuidado impacta praticamente em todas as capacidades centrais das cuidadoras. Relativamente às "necessidades gerais de capacidades" das assistentes, é fácil verificar que sofrem comprometimentos em sua saúde e em seu equilíbrio emocional (especialmente pela sobrecarga e porque veem desperdiçadas várias outras capacidades que poderiam aprimorar e desenvolver), bem como que inúmeras desvantagens que experimentam derivam de "benefícios sociais ruins" (NUSSBAUM, 2013, p. 209).

Conquanto não possa garantir a felicidade às cuidadoras, a sociedade justa pode/deve oferecer "um nível mínimo de capacidade em cada uma das áreas-chave"; exemplificativamente, no tocante ao equilíbrio emocional, "boas assistências sociais públicas e uma cultura pública digna", que "podem tornar possível que o cuidado de um idoso ou de um dependente deficiente não envolva a ansiedade constante sobre como o trabalho será feito, e com quais recursos", isto é, "políticas públicas que fizessem do cuidar de um dependente uma escolha real, não uma imposição nascida da indiferença social” (NUSSBAUM, 2013, p. 210). 
Nessa linha de raciocínio, entre as medidas a serem implementadas, estariam a ênfase, pela educação pública, da importância da assistência como parte da vida tanto dos homens quanto das mulheres, visando "romper com a relutância que os homens têm em fazer tais trabalhos, bem como a transformação do local de trabalho através de novas normas éticas e de flexibilidade. Dessarte, o enfoque das capacidades refuta a "distinção liberal comum" das esferas pública e privada e compreende a família como uma "instituição social e política", integrante da "estrutura básica da sociedade”, preocupando-se com a distribuição de recursos e oportunidades no seu seio. Assim, caso os limites às capacidades decorram de circunstâncias e de condições da estrutura familiar, sendo viável que isso seja coibido ou evitado por meio de mecanismos legais, incumbirá ao Estado atuar neste sentido, promovendo uma estrutura mais adequada (NUSSBAUM, 2013, p. 223, 261/262).

Desse modo, acredita-se que as mulheres poderiam ter, efetivamente, a possibilidade de escolher/decidir seu "plano de vida", bem como de definir "que papel o cuidado de dependentes teria nele", dispondo também de tempo para o lazer e para o engajamento em outras atividades conectadas com várias capacidades da lista (NUSSBAUM, 2013, p. 210).

À luz das ideias kantianas acerca da dignidade - válidas a diversas teorias de justiça -, toda pessoa deve ser tratada como um fim e não subordinada à "causa do bem-estar geral", tampouco violada em prol de um "benefício social maior" (NUSSBAUM, 2013, p. 159 e 182). Nesse passo, lançando mão de um argumento liberal clássico, Nussbaum (2013, p. 268) sustenta que é preciso lembrar que "os cuidadores (care-givers) têm suas próprias vidas para levar, e por isso devemos apoiar políticas que lhes deem mais chances", bem como defende que os assistentes sejam reconhecidos como "trabalhadores ativos e dignos, em vez de contribuintes passivos".

Em suma, sob as diretrizes do enfoque das capacidades, a sociedade seria edificada e estruturada visando possibilitar aos indivíduos que desfrutem da totalidade das capacidades elencadas na lista, não em função da "produtividade social" e sim porque consiste em algo "humanamente bom" que todos os cidadãos tenham a oportunidade de "desenvolver o âmbito total das faculdades humanas" (NUSSBAUM, 2013, p. 269). 


\section{CONCLUSÃO}

Três premissas orientaram os argumentos centrais dessa artigo, a saber: a) a dicotomia público/privado hierarquiza as dimensões da vida humana e justifica a desigualdade de gênero; b) a divisão sexual do trabalho limita as opções de escolha das mulheres e "naturaliza" o cuidado como atividade feminina e c) o cuidado como tarefa exclusiva da mulher e o tratamento da família como instituição não-política dificulta o desenvolvimento das capacidades das mulheres.

Elas foram desenvolvidas nas três partes apresentadas. Para justificálas e esclarecê-las as subsequentes ponderações foram propostas:

1. A dicotomia público-privado, originária do pensamento grego, naturaliza papéis sociais e restringe as mulheres ao "espaço privado";

2. A desigualdade de gênero está impregnada em diversas relações, derivando da histórica da atribuição sexista de papéis sociais, sendo reproduzida pelas estruturas de poder e impondo inúmeras dificuldades às mulheres;

3. A divisão sexual do trabalho, com a imputação da responsabilidade pelas tarefas domésticas e pelo cuidado essencialmente às mulheres, consiste em aspecto determinante para a exclusão e o estabelecimento/ manutenção de desvantagens das mulheres. 0 tempo e a energia despendidos no exercício de tais atividades, bem como as limitações que implicam à trajetória de mulheres e a desvalorização do trabalho prestado gratuitamente na vida cotidiana são evidentes;

4. Essas circunstâncias impactam no desenvolvimento de mulheres e, consoante teoria elaborada por Martha Nussbaum, em suas capacidades. Para alterar tal cenário de iniquidade, especialmente no seio familiar, é preciso compreender que o que ocorre nos espaços considerados privados tem expressiva relevância e reflexos no âmbito público, não podendo ficar imune à justiça.

Retomando a perspectiva invertida e o questionamento inicialmente proposto, a saber: se for adotado pressupostos distintos dos construídos 
historicamente, ou seja, de que a família é uma instituição política, de que o afeto e cuidado são bens sociais básicos, de que o trabalho doméstico se equipara e tem o mesmo valor do trabalho não-doméstico, quais seriam os avanços teóricos que poderiam se configurar?

Ao se pensar a família como instituição política a ideia de justiça ingressa no ambiente intrafamiliar torna-o mais democrático e saudável, a tarefa do cuidado passa a ser valorizada e melhor distribuída e por fim, ocorre o desbloqueio de alguns trajetos que impedem as mulheres de desenvolver adequadamente suas capacidades.

\section{REFERÊNCIAS}

ALMEIDA, S.S. Violência de gênero: público $\mathbf{X}$ privado. Tese (Doutorado em Ciências Sociais) - Pontifícia Universidade Católica de São Paulo. São Paulo, 1997.

ARENDT, Hannah. A condição humana. 10ª ed., Rio de Janeiro: Forense Universitária, 2007.

BELEZA, Tereza Pizarro. Direito das mulheres e da igualdade social. A construção jurídica das relações de gênero. Coimbra: Almedina, 2010.

BIROLI, Flávia; MIGUEL, Luis Felipe. Gênero, raça, classe: opressões cruzadas e convergências na reprodução das desigualdades. Dossiê - Desigualdades e Interseccionalidades. Mediações, Londrina, v. 20, n. 2, p. 27-55, jul./dez. 2015.

BIROLI, Flávia. Gênero e desigualdades: os limites da democracia no Brasil. São Paulo: Boitempo, 2018.

HABERMAS, Jürgem. A mudança estrutural da esfera pública. Rio de Janeiro: Tempo Brasileiro, 1984.

INSTITUTO BRASILEIRO DE GEOGRAFIA E ESTATISTICA (IBGE). Estatísticas de gênero: responsabilidade por afazeres afeta inserção das mulheres no mercado de trabalho. Disponível em: <https://agenciadenoticias.ibge.gov.br/agencia-salade-imprensa/2013-agencia-de-noticias/releases/20232-estatisticas-de-generoresponsabilidade-por-afazeres-afeta-insercao-das-mulheres-no-mercado-detrabalho.html>. Acesso em: 23 de julho de 2018. 
INSTITUTO DE PESQUISA ECONÔMICA APLICADA (IPEA). Retrato das desigualdades de gênero e raça - 1995 a 2015. Disponível em: <http://www. ipea.gov.br/portal/index.php?option=com_content\&view=article\&id=29526>. Acesso em 24 de agosto de 2018.

KYMLICKA, Will. Filosofia Política Contemporânea. São Paulo: Martins Fontes, 2006.

NUSSBAUM, Martha C. Women and human development. The capabilities approach. Cambridge: Cambridge University Press, 2000.

NUSSBAUM, Martha C. Fronteiras da justiça. Deficiência, nacionalidade, pertencimento à espécie. 1aㅡ ed. São Paulo: WMF Martins Fontes, 2013.

OKIN, Susan Moller. Women in Western Political Thought. Princeton: Princeton University Press, 1979.

OKIN, Susan Moller. Gênero, público e privado. Revista Estudos Feministas. vol.16, no.2, Florianópolis, Mai./Ago. 2008.

PERROT, M. Escrever uma história das mulheres: relato de uma experiência. Cadernos Pagu, n 4. Núcleo de estudos de gênero, IFCH-UNICAMP, 1995.

RAWLS, John. Justiça como equidade. São Paulo: Martins Fontes, 2003 RAWLS, John. Uma Teoria da Justiça. São Paulo: Martins Fontes, 2003 SAFFIOTI, Heleieth. O poder do macho. São Paulo: Moderna, 1990.

SEN, Amartya. A ideia de Justiça. São Paulo: Companhia das letras, 2011.

SEN, A. Capability and Well-Being. In: NUSSBAUM, M.; SEM, A. The Quality of Life. New York, Oxford University Press, 1993.

SEN, A. Equality of What? In: MCMURRIN, S. Tanner Lectures on Human Values. Cambridge: Cambridge University Press, 1980. v. 1. 
STRAPAZZON, Carlos Luiz; TRAMONTINA, Robison. Justiça e Direitos na perspectiva de Martha Nussbaum. IN: STRAPAZZON, Carlos Luiz; TRAMONTINA, Robison. Teorias da Justiça e Teorias da Segurança Social. Joaçaba: Editora Unoesc, 2017.

Recebido em: 9-11-2020

Aprovado em: 8-12-2020

\section{Robison Tramontina}

Doutor em Filosofia pela Pontifícia Universidade Católica do Rio Grande do Sul - PUCRS ( CAPES 6). Coordenador do Programa de Pós - Graduação em Direito (Mestrado e Doutorado) da Universidade do Oeste de Santa Catarina (UNOESCCAPES 4). Professor de Filosofia do Direito, Argumentação Jurídica e Teorias da Justiça. Atua na Linha de Pesquisa: Fundamentos Filosóficos dos Direitos Humanos/Fundamentais e Teorias da Justiça. Os principais temas de pesquisa são: a) Teorias da Justiça; b) Justiça Distributiva e os direitos fundamentais; c) Filosofia da Segurança Social, d) Fundamentos filosóficos do Mundo do Trabalho e e) Obrigações Políticas. Revisor de diversos periódicos. ORCID: 0000-00021852-4983. E-mail: robison.tramontina@unoesc.edu.br

\section{Larissa Thielle Arcaro}

Mestra em Direito, especialista em Direito Processual Civil e graduada em Direito pela Universidade do Oeste de Santa Catarina. Assessora de gabinete no Tribunal de Justiça de Santa Catarina. E-mail: larissat_smo@hotmail.com.

Universidade do Oeste de Santa Catarina. Programa de Pós-graduação em Direito. Rua Getúlio Vargas, 2125 - Bairro Flor da Serra. Joaçaba - SC - CEP 89600-000 